ASTHMA

\title{
Fluticasone induces T cell apoptosis in the bronchial wall of mild to moderate asthmatics
}

\author{
S O'Sullivan, L Cormican, C M Burke, L W Poulter
}

Thorax 2004;59:657-661. doi: 10.1136/thx.2002.001586

See end of article for authors' affiliations ....................

Correspondence to: Dr S O'Sullivan, Department of Immunology, Royal Free and University College Hospital Medical School, London NW3 2QG, UK; sioosu@indigo.ie

Received 27 January 2003 Accepted 7 February 2004

\begin{abstract}
Background: Cytokines which signal via the gamma chain of the interleukin (IL)-2 receptor and the interferons (IFNs) have been shown to enhance T cell survival in vitro by rescuing cells from apoptosis. Methods: A study was undertaken to determine whether treatment with inhaled fluticasone propionate (FP; $250 \mu \mathrm{g}$ twice daily) for 2 weeks could modulate production of IL-15 or IFN- $\beta$ and thereby affect T cell survival in bronchial tissue of 10 patients with mild/moderate asthma. Bronchial biopsy specimens were taken before and on completion of treatment.

Results: The mean $(95 \% \mathrm{Cl})$ number of T cells per unit area decreased in the asthmatic group following 2 weeks of treatment with FP (from 7.0 (5.6 to 8.4) to 4.5 (4.0 to 5.1); $p=0.001$ ). There was an increase in the percentage of T cells undergoing apoptosis following FP treatment as assessed by T cell/TUNEL staining (from 4.5 (2.6 to 6.4 ) to 8.7 (6.6 to 10.8); $p=0.0001$ ). The percentage of cells staining for IL-15 and IFN- $\beta$ in the lamina propria, determined by an alkaline phosphatase biotin streptavidin technique, decreased significantly from baseline values of 31.6 (23.4 to 39.7) to 19.6 (12.5 to 26.7), $p=0.039$ for IL-15 and from 18.9 (13.5 to 24.4 ) to 9.5 (5.9 to 13.1), $p=0.007$ for IFN- $\beta$ following 2 weeks of treatment with FP. However, only the decrease in the percentage of cells staining for IL-15 was significantly correlated with an increased number of apoptotic T cells following treatment $(p=0.008)$.

Conclusion: These findings support a novel mechanism for the ability of inhaled corticosteroids to decrease T cell numbers, possibly by downregulation of the cytokine IL-15.
\end{abstract}

A poptosis has emerged as a major mechanism for the clearance of activated $\mathrm{T}$ cells during the resolution of an inflammatory response. ${ }^{1}$ It has been proposed that dysregulation of the survival and apoptosis of inflammatory cells has a central role in chronic inflammation. ${ }^{2-4}$

Activated $\mathrm{T}$ cell apoptosis can occur via two distinct pathways: activation induced cell death involves ligation between FAS and its ligand ${ }^{5}$ while cytokine deprivation death of activated $T$ cells tends to occur at the end of the immune response. ${ }^{6}$ Withdrawal of cytokines-specifically those which signal via the $\gamma$-chain of the interleukin (IL)-2 receptor (IL2R), IL-2, IL-4, IL-7 and IL-15-leads to apoptosis associated with the downregulation of the anti-apoptotic molecule Bcl$2 .^{7}$ Deprivation of a second group of cytokines, the type I interferons (IFNs), also results in T cell apoptosis, ${ }^{8}$ but Bcl-2 expression does not appear to be central to this process. ${ }^{9}$

Compelling evidence has recently accumulated which attests to a defect in the regulation of apoptosis in asthma. ${ }^{10-12}$ Asthma is characterised by a chronic inflammation of the bronchial wall dominated by $\mathrm{T}$ lymphocytes and eosinophils. ${ }^{13}$ The accumulation of these cells in the asthmatic airway significantly contributes to the persistence of airway inflammation in these patients. Wolley et al have found decreased numbers of eosinophils undergoing apoptosis in asthmatic subjects compared with a non-asthmatic control group..$^{14}$ In addition, eosinophil expression of the antiapoptotic gene product Bcl-2 is increased in bronchial biopsy material from asthmatic subjects. ${ }^{11}$ The role of $\mathrm{T}$ cell apoptosis has only recently received any attention. Spinozzi et al recently reported hypoexpression of FAS mRNA and its receptor FAS ligand, two molecules necessary for activation induced cell death, by pulmonary $\mathrm{T}$ cells isolated from bronchoalveolar lavage (BAL) fluid of subjects with atopic asthma. ${ }^{15}$

Previous observations from our laboratory have shown a reduction in the expression of $\mathrm{Bcl}-2$ by the $\mathrm{CD} 4+\mathrm{T}$ cell population in asthmatic subjects compared with a nonasthmatic control group. ${ }^{16}$ Furthermore, IFN- $\gamma$ positive but not IL-4 positive T cells in biopsy specimens from asthmatic subjects had significantly higher proportions of apoptotic cells, supporting the hypothesis that a Th1/Th2 imbalance in asthmatic inflammation may be a result of premature apoptosis within the Thl subset. ${ }^{16}$

Corticosteroids constitute first line therapy in the treatment of asthma. ${ }^{17} \mathrm{~A}$ number of biopsy studies have confirmed that corticosteroids reduce the number and activation status of inflammatory cells in the asthmatic bronchial wall. ${ }^{18}{ }^{19}$ Corticosteroid administration in asthmatic subjects results in an increase in the proportion of apoptotic eosinophils in tissue biopsy specimens ${ }^{11}$ and sputum. $^{14}$ Corticosteroids have also been shown to promote the apoptotic death of unstimulated and stimulated peripheral blood $\mathrm{T}$ lymphocytes ex vivo. ${ }^{20} 21$

The aim of the present study was to evaluate the effect of the inhaled corticosteroid fluticasone propionate (FP) on apoptosis of $\mathrm{T}$ lymphocytes in the bronchial submucosa of asthmatic subjects. We also wished to determine whether downregulation of IL-15 and IFN- $\beta$ by corticosteroids constituted a possible mechanism for any $\mathrm{T}$ cell apoptosis observed.

\section{METHODS \\ Subjects}

Ten non-smoking atopic subjects with mild to moderate asthma were recruited into the study (table 1). All had been non-smokers for at least 10 years before the study. The atopic status was established by positivity to one or more of 10 routinely tested allergens by skin prick testing (Bayer Corporation, Elhart, USA). All of the subjects were newly diagnosed asthmatics who were steroid naïve before enrolment into the study and used $\beta$ agonists on an as needed basis. A comparable asthmatic control group was not 
included as it was deemed unethical to withhold or withdraw treatment from patients with mild/moderate asthma. Eight subjects with no history of asthma, negative skin prick tests, and negative RAST to the same allergens constituted a control group. These subjects were life long non-smokers, had not previously been treated with corticosteroids, and had pulmonary function tests within normal limits. Exclusion criteria included a respiratory tract infection in the 6 weeks before the study.

The ethics committee of the hospital and the Irish Medicines Board approved the study and all patients gave written informed consent prior to participation.

\section{Study design}

Patients received $250 \mu \mathrm{g}$ FP twice daily for 2 weeks delivered by a pressurised canister through a Volumatic device. A 2 week treatment regime was used as previous data from this laboratory have shown a decrease in $\mathrm{T}$ cells following a 2 week intervention with $\mathrm{FP}^{22}$ Subjects were also provided with a salbutamol pressurised rescue inhaler ( $100 \mu \mathrm{g} / \mathrm{puff}$ ) for use during the treatment period on an as needed basis for symptomatic relief. Bronchoscopy was performed the day before treatment and \pm 2 days after the 2 week treatment period with FP. The control group did not receive any medication and underwent a single bronchoscopic examination.

\section{Bronchoscopy}

Three endobronchial biopsy specimens were obtained from the second to fourth generation bronchi on the right side under general anaesthesia as previously described. ${ }^{22}$ Biopsy material was immediately snap frozen in isopentane $(\mathrm{BDH}$, Poole, UK), cooled to $-80^{\circ} \mathrm{C}$, and stored in liquid nitrogen. Sections $6 \mu \mathrm{m}$ in thickness were subsequently cut from the specimens onto poly-L-lysine glass slides (BDH, Poole, UK). The integrity and architecture of the tissue was confirmed by staining with toluidine blue dye. Sections were then air dried for 1 hour, fixed in chloroform:acetone $1: 1$ solution for 10 minutes, and air dried again for a further 20 minutes before storage at $-20^{\circ} \mathrm{C}$.

\begin{tabular}{|c|c|c|c|c|}
\hline & $\begin{array}{l}\text { Age } \\
\text { (years) }\end{array}$ & Sex & $\begin{array}{l}\mathrm{FEV}_{1} \\
\text { (\% pred) }\end{array}$ & $\begin{array}{l}\mathrm{PC}_{20} \\
(\mathrm{mg} / \mathrm{ml})\end{array}$ \\
\hline \multirow[t]{10}{*}{ Asthmatics } & 34 & $M$ & 92 & 0.04 \\
\hline & 28 & $\mathrm{~F}$ & 87 & 0.07 \\
\hline & 36 & M & 76 & 0.17 \\
\hline & 31 & M & 81 & 0.33 \\
\hline & 36 & M & 77 & 0.05 \\
\hline & 36 & M & 80 & 1.5 \\
\hline & 31 & M & 80 & 0.18 \\
\hline & 51 & M & 104 & 0.2 \\
\hline & 27 & M & 77 & 1.4 \\
\hline & 28 & M & 99 & 1.8 \\
\hline Mean (SE) & $33.8(2.2)$ & $9 \mathrm{M} / 1 \mathrm{~F}$ & $85.3(3.1)$ & $0.57(0.2)$ \\
\hline \multirow[t]{8}{*}{ Controls } & 51 & M & 98 & \\
\hline & 83 & M & 85 & \\
\hline & 52 & M & 109 & \\
\hline & 53 & M & 127 & \\
\hline & 41 & M & 91 & \\
\hline & 46 & M & 110 & \\
\hline & 52 & M & 88 & \\
\hline & 65 & M & & \\
\hline Mean (SE) & $55.4(4.6)$ & $8 \mathrm{M} / \mathrm{OF}$ & $100.6(4.9)$ & \\
\hline
\end{tabular}

$\mathrm{FEV}_{1}=$ forced expiratory volume in 1 second; $\mathrm{PC}_{20}=$ concentration of methacholine required to provoke a fall in $\mathrm{FEV}_{1}$ of $20 \%$ or more.

\section{T cell numbers}

Absolute numbers of $\mathrm{T}$ cells per unit area were identified using a cocktail of CD2, CD3, CD5, and CD8 ( $\mathrm{T}$ mix) monoclonal antibodies by an indirect immunoperoxidase method as previously described.$^{22}$ This T cell cocktail has been shown to identify more than $99 \%$ of T cells from suspensions of human peripheral blood and bone marrow. ${ }^{23}$ Validation of the method for identifying $\mathrm{T}$ cells in bronchial biopsies has not been published. Endogenous peroxidase activity from eosinophils and mast cells was excluded by the use of negative controls in which the $\mathrm{T}$ cell monoclonal antibody layer was omitted. All slides were coded and counted in a blind fashion by two observers. Data presented are the mean values of data recorded by the two observers. A minimum of five areas in the subepithelial region were analysed and the total number of $\mathrm{T}$ cells per unit area $\left(10^{4} \mu \mathrm{m}^{2}\right)$ were determined using a computerised image analysis system (Axiocam, Zeiss, Jena, Germany).

\section{Identification of apoptotic T cells}

The proportion of apoptotic T cells was determined using a combination of indirect immunofluorescence and TUNEL (terminal deoxynucleotidyl transferase mediated dUTP nick end labelling). Sections were allowed to equilibrate to room temperature and were incubated with mouse anti-human (MAH) CD2+, CD3+, CD4+, CD5+ and CD8+ IgM at a $1 / 5$ dilution in PBS ( $\mathrm{pH}$ 7.4) at room temperature in a humidified chamber for 45 minutes. Sections were then washed twice for 2 minutes in PBS pH 7.4. A second layer containing isotype and species specific fluorochrome conjugated antibody, goat anti-Mouse IgM TRITC (Southern Biotechnology Assoc, AL, USA) at a 1/50 dilution in PBS pH 7.4 was applied. The sections were permeabilised by the addition of Triton X100 permeabilisation solution (Rohm \& Haas, Philadelphia, USA) at $4^{\circ} \mathrm{C}$ for 2 minutes. TUNEL terminal deoxynucleotidyl dUTP nick end labelling solution (Fluorescein-Boehringer Mannheim, IN, USA) was then applied to each test specimen. The reaction mixture contained $50 \mu$ terminal deoxynucleotidyl transferase from calf thymus and $450 \mu \mathrm{l}$ fluorochrome conjugated nucleotide dUTP. In the negative control the reaction mixture was omitted. The sections were then washed three times in PBS pH 7.4 before fixation in Citifluor (Citifluor Ltd, Kent, UK). Sections of human tonsil were used as positive controls and negative controls consisted of sections incubated using a solution with terminal transferase instead of the TUNEL reaction mixture. All slides were coded and counted in a blind fashion by two observers. Data presented are the mean of data recorded by the two observers. The proportion of TUNEL positive $\mathrm{T}$ cells was estimated using a Zeiss fluorescence microscope with epiillumination and barrier filters for FITC and TRITC. A minimum of five high power fields $(\times 40)$ were examined (each containing at least 20 cells).

\section{Cytokine analysis}

The number of cells expressing IL- 15 and IFN- $\beta$ was assessed with a biotin-alkaline phosphatase-streptavidin technique. Briefly, sections were fixed in methanol:acetone $1: 1$ for 10 minutes at $-20^{\circ} \mathrm{C}$ and then washed in PBS pH 7.4. Mouse anti-human IL-15 (Pharmingen, CA, USA) and sheep antihuman IFN- $\beta$ (Pharmingen) were diluted 1 in 10 and 1 in 30, respectively, in PBS $+1 \%$ BSA and incubated overnight. Sections were washed in Tris-buffered saline (TBS) pH 7.6 and then incubated with $50 \mu$ of an IgG affinity purified horse anti-mouse biotinylated second layer (Vector Laboratories, Peterborough, UK) diluted $1 / 100$ in PBS-BSA for 1 hour at room temperature. After rinsing in fresh TBS the sections were incubated with $50 \mu \mathrm{l}$ streptavidin-alkaline phosphatase (Vector Laboratories) diluted $1 / 100$ in PBS-BSA 
for 1 hour at room temperature. The sections were again rinsed in fresh TBS and the reaction was developed by a 15 minute application of a substrate solution $(5 \mathrm{mg}$ naphthol ASBI phosphate, $10 \mathrm{ml}$ Tris- $\mathrm{HCl}(\mathrm{pH} 8.2), 200 \mu \mathrm{l}$ dimethylformamide, $10 \mathrm{mg}$ Fast Red, and 10 drops of levamisole added just before use). The sections were then washed in tap water, distilled water, and counterstained with Mayer's haematoxylin before mounting in 9:1 PBS:glycerol. The primary antibody layer was omitted in the negative control sections. All slides were coded and counted in a blind fashion by two observers. Data presented are the mean of data recorded by the two observers. Positively stained areas in a minimum of $3-5$ framed areas $\left(10^{4} \mu \mathrm{m}^{2}\right)$ in the lamina propria (15 cell depth) were quantified using an image analysis system (Axiocam, Zeiss, Jena, Germany). The immunostained area was divided by the field area measurement and expressed as the percentage stained area.

\section{Data analysis}

The data were normally distributed (as assessed by the Kolmogorov-Smirnov test) and are expressed as mean values with $95 \%$ confidence intervals (CI). Changes in group means from baseline following treatment were compared using the Student's paired $t$ test. Comparisons between cytokine levels in asthmatic and non-asthmatic subjects were performed with an unpaired $t$ test. Correlation coefficients $(r)$ were calculated using Pearson's product moment correlation analysis. A p value of $<0.5$ was considered significant. The statistical calculations were performed using a validated statistical software package for personal computers (SigmaStat 2.0, Jandel Scientific, USA).

\section{RESULTS}

All bronchial biopsy specimens from subjects with asthma contained a subepithelial inflammatory infiltrate which was not present in the control biopsies. The mean (95\% CI) number of $\mathrm{T}$ cells per unit area decreased significantly in the asthma group following treatment for 2 weeks with $250 \mu \mathrm{g}$ FP twice daily (from 7.0 (5.6 to 8.4) to 4.5 (4.0 to 5.1), $\mathrm{p}=0.001$; fig $1 \mathrm{~A})$. This decrease in $\mathrm{T}$ cell number was reflected by an increase in the percentage of $\mathrm{T}$ cells undergoing apoptosis following FP treatment (from 4.5 (2.6 to 6.4) to 8.7 (6.6 to 10.8$), \mathrm{p}=0.000 \mathrm{l}$; fig $\mathrm{lB}$ ). We have previously reported a decreased number of $\mathrm{T}$ cells and TUNEL positive $\mathrm{T}$ cells in biopsy specimens from subjects with asthma compared with biopsies from non-asthmatic subjects. ${ }^{16}$

The percentage of cells staining positive for IL-15 in the lamina propria was twice as high in the pretreatment biopsy specimens of the asthma group than in biopsy specimens from the non-asthmatic control group (31.6 (23.4 to 39.7) $\mathrm{v}$ $16.0(12.9$ to 19.2$) ; p=0.002)$. Furthermore, there was a significant decrease in the percentage of cells staining positive for IL-15 in the lamina propria of the asthmatic group following treatment with FP (19.6 (12.5 to 26.7), $\mathrm{p}=0.039$; fig 2A). A significant correlation was observed between the increased number of apoptotic T cells and the decrease in the percentage of cells staining for IL-15 in the lamina propria $(r=-0.85 ; \mathrm{p}=0.008)$.

The percentage of cells staining positive for IFN- $\beta$ in the lamina propria was significantly higher in pretreatment biopsy specimens from asthmatic subjects than in nonasthmatic biopsy specimens ( 18.9 (13.5 to 24.4) $v 9.76$ (4.1 to 15.4), $\mathrm{p}=0.017$; fig $2 \mathrm{~B}$ ). Following treatment with FP there was a significant decrease in the percentage of cells staining for IFN- $\beta$ in the biopsy specimens from subjects with asthma (9.5 (5.9 to 13.1), $\mathrm{p}=0.007$; fig $2 \mathrm{~B}$ ). The decrease in the percentage of cells staining for IFN- $\beta$ was not correlated with the increase in apoptotic T cells $(r=0.12 ; \mathrm{p}=0.8)$.
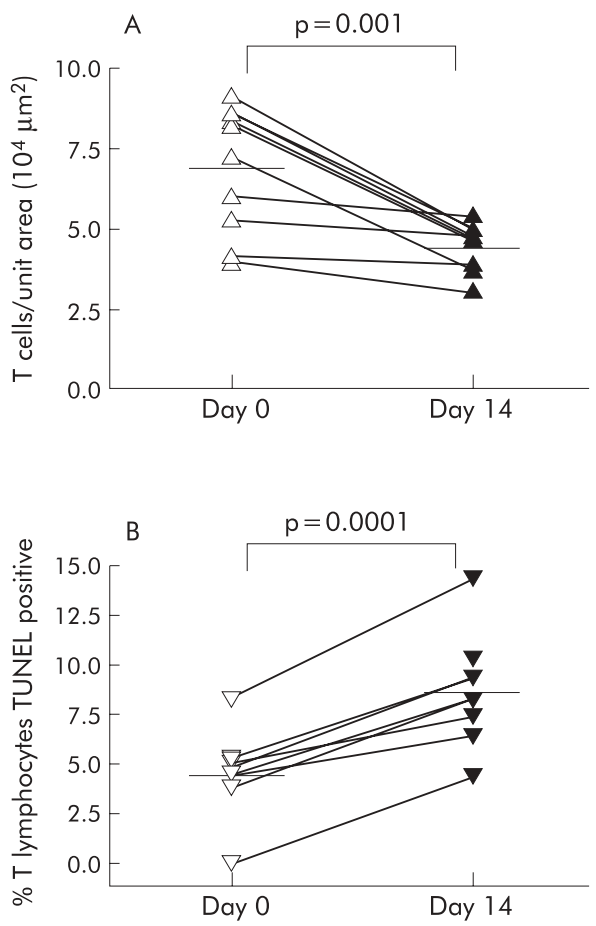

Figure 1 Individual data points of $(\mathrm{A})$ the number of $\mathrm{T}$ cells per $10^{4} \mu \mathrm{m}^{2}$ and (B) the percentage of T cells undergoing apoptosis in bronchial biopsy specimens from subjects with asthma before and after 2 weeks of treatment with $250 \mu \mathrm{g}$ fluticasone propionate. Mean values are denoted by horizontal lines.
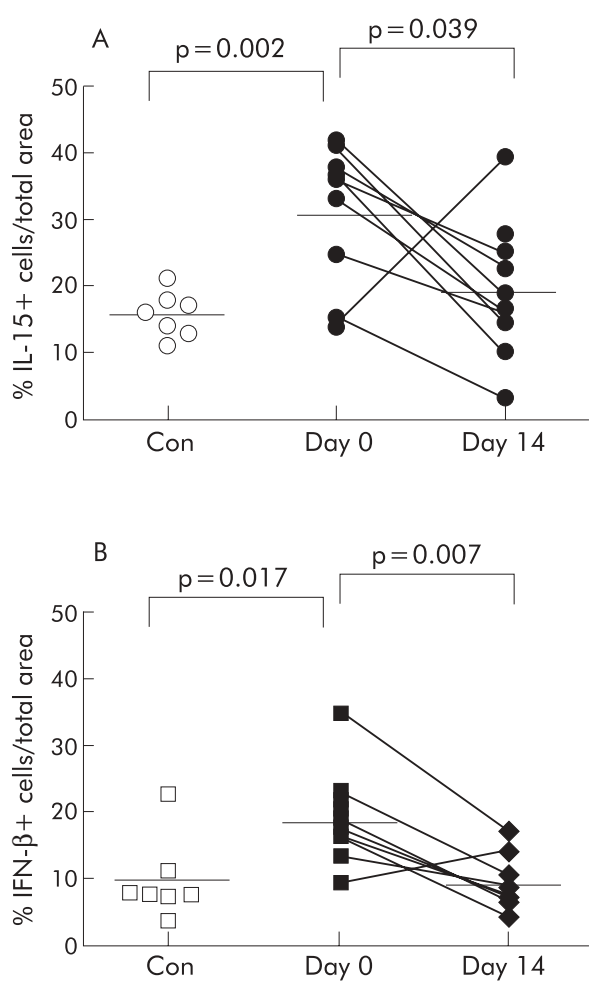

Figure 2 Individual data points of percentage of cells staining positive for (A) IL-15 and (B) IFN- $\beta$ in non-asthmatic and steroid naïve asthmatic bronchial biopsies. Following treatment with $250 \mu \mathrm{g}$ fluticasone propionate for 2 weeks the percentage of cells staining positive for both IL-15 and IFN- $\beta$ decreased significantly in biopsy specimens from asthmatic subjects. Mean values are denoted by horizontal lines. 


\section{DISCUSSION}

The treatment of steroid naïve subjects with mild/moderate asthma with $250 \mu \mathrm{g}$ FP twice daily resulted in a decrease in T cell numbers and in increased apoptosis of the $\mathrm{T}$ lymphocyte population of the bronchial wall. While the ability of inhaled corticosteroids to decrease $\mathrm{T}$ cell numbers in the bronchial submucosa is well established, ${ }^{18}{ }^{22}$ to the best of our knowledge these data represent the first report of a pro-apoptotic effect of inhaled steroids on the T lymphocyte population in vivo.

The anti-inflammatory effect of corticosteroids, mediated via alterations in the apoptosis of inflammatory cells, has previously been addressed. It is increasingly recognised that prolonged eosinophil survival through inhibition of apoptosis contributes to the eosinophilic inflammation in asthma. ${ }^{1424}$ Furthermore, the use of inhaled corticosteroids has been shown to reverse the delayed eosinophil apoptosis in asthma both in vivo and in vitro. ${ }^{1125}$ The pro-apoptotic effects of steroids may be a consequence of a direct effect on eosinophil apoptosis $^{25}$ or of an inhibition of pro-survival cytokines such as IL-5 and granulocyte-macrophage colony stimulating factor (GM-CSF). ${ }^{26}$

More recently there have been a number of reports that support a similar defect in T cell apoptosis in asthma. ${ }^{10} 1516$ Hamzaoui et $\mathrm{l}^{27}$ found decreased numbers of T lymphocytes undergoing apoptosis in induced sputum from asthmatic subjects compared with non-asthmatic controls. Culture of peripheral blood lymphocytes isolated from non-asthmatic subjects with the steroids dexamethasone and prednisolone has been shown to promote $\mathrm{T}$ cell apoptosis in a dose and time dependent fashion. ${ }^{20} 28$ Melis et al ${ }^{21}$ have recently published data which show that FP induces apoptosis in peripheral blood $\mathrm{T}$ lymphocytes from asthmatics with an associated decrease in the expression of Bcl-2 and FAS. In vivo evidence for an effect of corticosteroids on $\mathrm{T}$ cell apoptosis in asthma is currently lacking. A small but nonsignificant increase in the percentage of $\mathrm{T}$ lymphocytes undergoing apoptosis in the bronchial submucosa of asthmatic subjects treated with inhaled corticosteroids compared with steroid naïve asthmatics has been reported. ${ }^{11}$ This was a comparative study between two discrete asthmatic groups performed at a single time point, perhaps explaining why their findings differ slightly from the results reported here.

In this study production of the pro-survival cytokines IL-15 and IFN- $\beta$ was greater in the bronchial wall of steroid naïve asthmatic subjects than in non-asthmatic controls, thereby providing a microenvironment within the asthmatic airways which mitigates against apoptosis of the $\mathrm{T}$ lymphocyte population. Moreover, following treatment with FP for 2 weeks the percentage of cells staining for both cytokines in the lamina propria returned to control levels, with an associated increase in $\mathrm{T}$ lymphocyte apoptosis. These data provide evidence to support cytokine deprivation as a possible mechanism by which inhaled corticosteroids produce an increase in Tymphocyte apoptosis in the bronchial wall.

Overexpression of the anti-apoptotic cytokines IL-15 and IFN- $\beta$ has been implicated in the genesis of other chronic inflammatory diseases. ${ }^{29}$ Highly differentiated synovial $\mathrm{T}$ cells are actively inhibited from undergoing apoptosis in the rheumatoid synovium. ${ }^{2}$ Removal of these $\mathrm{T}$ cells from the inflamed rheumatoid joint leads to rapid apoptosis, a process which can be reversed in vitro by the addition of either by IL-2R gamma chain signalling cytokines, including IL-15 or IFN- $\beta$ to activated synovial T cells. ${ }^{2}$ These two cytokines rescue $\mathrm{T}$ cells from death by different mechanisms. The common $\gamma$-chain cytokines prevent apoptosis by upregulating the expression of the anti-apoptotic protein Bcl-2 and Bcl-XL relative to $\mathrm{Bax}$, a pro-apoptotic homologue of $\mathrm{Bcl}-2 .^{7}$ In contrast, interferons act by a distinct intracellular pathway that does not affect Bcl-2 expression. ${ }^{9}$ As we did not examine $\mathrm{T}$ lymphocyte expression of Bcl-2 or Bcl-XL in this study, we cannot ascertain the relative contributions of either IL-15 or IFN- $\beta$ to the T lymphocyte apoptosis which resulted following their dowregulation by treatment with inhaled corticosteroids. However, the lack of any correlation between the increase in the number of apoptotic T cells and the decrease in the percentage of cells staining for IFN- $\beta$ in the lamina propria following treatment with FP would suggest that IFN$\beta$ is not central to this process.

Interestingly, Melis et $a l^{21}$ reported a significant decrease in $\mathrm{Bcl}-2$ expression in peripheral blood $\mathrm{T}$ lymphocytes following incubation with FP. In the current study the strong correlation observed between the decrease in the percentage of cells staining for IL-15 in the lamina propria and the decrease in the number of apoptotic $\mathrm{T}$ cells may suggest that the common $\gamma$-chain cytokines are indeed central to the process of inhaled corticosteroid induced apoptosis in asthma.

\section{ACKNOWLEDGEMENTS}

The authors thank Ms Huda Al Doujaily for technical assistance and gratefully acknowledge the support of GlaxoSmithKline R\&D, UK and the Eastern Health Board, Ireland.

\section{Authors' affiliations}

S O'Sullivan, L W Poulter, Department of Immunology, Royal Free and University College Hospital Medical School, London NW3 2QG, UK L Cormican, C M Burke, Department of Respiratory Medicine, James Connolly Memorial Hospital, Dublin 15, Ireland

\section{REFERENCES}

1 Akbar AN, Salmon M. Cellular environments and apoptosis: tissue microenvironments control activated T cell death. Immunol Today 1997; 18:72-6.

2 Salmon M, Scheel-Toellner D, Huissoon AP, et al. Inhibition of T cell apoptosis in the rheumatoid synovium. Eur J Immunol 1999;29:1041-50.

3 Solary E, Dubrez L, Eymin B. The role of apoptosis in the pathogenesis and treatment of diseases. Eur Respir J 1996;9:1293-305.

4 Salmon M, Pilling D, Borthwick NJ, et al. Inhibition of T cell apoptosis: a mechanism for the persistence of chronic inflammation. Immunologist 1997:5:87-92.

5 Alderson MR, Tough TW, Davis ST, et al. Fas ligand mediates activation-induced cell death in human T lymphocytes. J Exp Med $1995 ; 181: 71-7$.

6 Vella AT, Dow S, Potter TA, et al. Cytokine-induced survival of activated T cells in vitro and in vivo. Proc Natl Acad Sci USA 1998;95:3810-5.

7 Akbar AN, Borthwick NJ, Wickremasinghe RG, et al. Interleukin-2 receptor common gamma-chain signalling cytokines regulate activated T cell apoptosis in response to growth factor withdrawal: selective induction of anti-apoptotic (bcl-2, bcl-x(L) but not pro-apoptotic (bax, bcl-x(S)) gene expression. Eur J Immunol 1996;26:294-9.

8 Marrack P, Kappler J, Mitchell T. Type I interferons keep activated T cells alive. $J$ Exp Med 1999;189:521-9.

9 Pilling D, Akbar AN, Girdlestone J, et al. Interferon-beta mediates stromal cell rescue of T cells from apoptosis. Eur J Immunol 1999;29:1041-50.

10 Jayaraman S, Castro M, O'Sullivan M, et al. Resistance to Fas-mediated T cell apoptosis in asthma. J Immunol 1999;162:1717-22.

11 Druilhe A, Wallaert B, Tsicopoulos A, et al. Apoptosis, proliferation and expression of $\mathrm{Bcl}-2$, Fas, and Fas ligand in bronchial biopsies from asthmatics. Am J Respir Cell Mol Biol 1998;19:747-57.

12 Krug N, Tschernig T, Balke K, et al. Enhanced expression of Fas ligand (CD95L) on T cells after segmental allergen provocation in asthma. J Allergy Clin Immunol 1999;103:649-55.

13 Corrigan C, Kay A. T cells and eosinophils in the pathogenesis of asthma. Immunol Today 1992;13:501-6.

14 Wolley K, Gibson P, Carty K, et al. Eosinophil apoptosis and the resolution of airway inflammation in asthma. Am J Respir Crit Care Med 1996; 154:237-43

15 Spinozzi F, Fizzotti $M$, Agea $E$, et al. Defective expression of Fas messenger RNA and FAS receptor on pulmonary T cells from patients with asthma. Ann Intern Med 1998;128:363-9.

16 Cormican L, O'Sullivan S, Burke C, et al. IFN- $\gamma$ but not IL-4 T cells of the asthmatic bronchial wall show increased incidence of apoptosis. Clin Exp Allergy 2001;31:731-9.

17 Barnes $\mathbf{P}$. Current issues for establishing inhaled corticosteroids as the antiinflammatory agents of choice in asthma. J Allergy Clin Immunol 1998;101:S427-33. 
18 Diukanovic R, Wilson J, Britten $\mathrm{K}$, et al. Effect of an inhaled corticosteroid on airway inflammation and symptoms in asthma. Am Rev Respir Dis 1992; 145:669-74.

19 Wilson JW, Djukanovic R, Howarth PH, et al. Inhaled beclomethasone dipropionate downregulates airway lymphocyte activation in atopic asthma. Am J Respir Crit Care Med 1994;149:86-90.

20 Brunetti M, Martelli N, Colasante A, et al. Spontaneous and glucocorticoidinduced apoptosis in human mature T lymphocytes. Blood 1995;86:4199-205.

21 Melis M, Siena L, Pace E, et al. Fluticasone induces apoptosis in peripheral Tlymphocytes: a comparison between asthmatic and normal subjects. Eur Respir J 2002;19:257-66.

22 Faul J, Leonard C, Burke C, et al. Fluticasone propionate induced alterations to lung function and the immunopathology of asthma over time. Thorax 1998:53:753-61.

23 Granger S, Janossy G, Francis G, et al. Elimination of T-lymphocytes from human bone marrow with monoclonal T-antibodies and cytolytic complement. Br J Haematol 1982;50:367-74.

24 Vignola AM, Chanez P, Chiaparra G, et al. Evaluation of apoptosis of eosinophils, macrophages and T lymphocytes in mucosal biopsy specimens of patients with asthma and chronic bronchitis. J Allergy Clin Immunol 1999; 103:563-73.

25 Meagher LC, Cousin JM, Seckl JR, et al. Opposing effects of glucocorticoids on the rate of apoptosis in neutrophilic and eosinophilic granulocytes. J Immunol 1996;156:4422-8.

26 Bentley AM, Hamid Q, Robinson DS, et al. Prednisolone treatment in asthma: reduction in the numbers of eosinophils, T cells, tryptase-only positive mast cells, and modulation of IL-4, IL-5, and interferon-gamma cytokine gene expression within the bronchial mucosa. Am J Respir Cit Care Med 1996;153:551-6.

27 Hamzaoui A, Hamzaoui K, Salah H, et al. Lymphocyte apoptosis in patients with acute exacerbations of asthma. Mediators Inflamm 1999;8:237-43.

28 Lanza L, Scudeletti M, Puppo F, et al. Prednisolone increases apoptosis in in vitro activated human peripheral blood T lymphocytes. Clin Exp Immunol 1996; 103:482-90.

29 Orteu C, Rustin M, O'Toole E, et al. The inhibition of cutaneous T cell apoptosis may prevent resolution of inflammation in atopic eczema. Clin Exp Immunol $2000 ; 122: 150-6$

\section{LUNG ALERT}

Rhinitis and the severity of OSA

$\Delta$ Kramer MF, de la Chaux R, Fintelmann R, Rasp G. NARES: a risk factor for obstructive sleep apnea. Am J Otolaryngol 2004;25:173-7

$\mathrm{T}$

here is controversy regarding whether nasal congestion is a risk factor for the obstructive sleep apnoea syndrome (OSAS). NARES (non-allergic rhinitis with eosinophilia) is a rare form of rhinitis, presenting with typical symptoms of perennial disease in the presence of eosinophilic nasal inflammation but negative tests of atopy. This paper aimed to assess whether OSAS was more severe in patients with NARES $(n=10)$ than controls without nasal inflammation, matched for age and BMI $(n=16)$. The diagnosis of NARES was confirmed by testing nasal wash for eosinophilic cationic protein and analysing serum samples for total and specific IgE. OSAS was confirmed by polysomnography.

The results suggest that the polysomnographic indices of hypopnoea index, apnoeahypopnoea index, and minimal oxygen saturation were significantly worse $($ all $\mathrm{p}<0.01)$ in the patients with NARES. This paper reinforces previous research that suggests nasal inflammation may aggravate OSAS, and reminds chest physicians to be aware of treatable causes of rhinitis which may contribute to the severity of disease.

P Michael

Research Fellow, Department of Otolaryngology, St Bartholomew's Hospital, London, UK; philip.michael@virgin.net 